\title{
Hope and Advanced Breast Cancer: Engaging with the Parish Nursing Community to Explore Hope in Women with Advanced Breast Cancer in Nigeria
}

\author{
Agatha Ogunkorode, Lorraine Holtslander
}

\begin{abstract}
Aвstract Women with advanced breast cancer living in Nigeria face many obstacles and are very reliant on the support of faith communities, including parish nurses, who have a strong presence in Nigeria. Research with people with advanced cancer has shown the importance of hope as a source of strength and an important spiritual concept in their lives. Parish nursing focuses on the promotion of health within the context of the values, beliefs, and practices of the faith community. What distinguishes parish nursing care is the intentional integration of the body, mind, and spirit to create wholeness, health, and a sense of well-being even when the patient's illness is not curable. This specialty nursing practice holds that all persons are sacred and must be treated with respect and dignity. In line with these beliefs, the parish nurse serves her community with compassion, mercy, presence, and justice. Community-based research is needed to explore what hope means for women in Nigeria with advanced breast cancer, in order to build essential and innovative nursing knowledge and provide opportunities to identify meaningful interventions and ways the faith community can support these women, their families, and their communities.
\end{abstract}

KEYWORDS advanced breast cancer, palliative care, parish nursing, community-based research, faith community

According to GLOBOCAN (2012), breast cancer is the most common cancer among women in developing countries like Nigeria (World Health Organization [WHO], 2013a). Approximately $70-79 \%$ of women in Nigeria present with an advanced stage of the disease (Jedy-Agba et al., 2012). Despite this high incidence, there is paucity of literature exploring the hope and coping experiences of this population. In an African context, including Nigeria, a woman's breast is an organ whose psychological functions are as important as its physical determinant of feminine attractiveness; any illness that affects the breasts therefore has the potential of threatening the psychological and emotional well-being of women (Akin-Odanye, Asuzu, \& Popoola, 2011). Findings from a study in Zambia by Maree and Molonda (2015) suggest that women experience psychological distress during their diagnosis and treatment with advanced breast cancer. However, even when cure was not a feasible option, hope helped the women to cope during palliative care (Maree \&Molonda, 2015). In an integrative review of the literature on hope in palliative care, "living with hope" and "hoping for something" were identified 
as the two overarching themes of patients' hope (Kylmä, J., Duggleby, W., Cooper, D., \& Molander, G., 2009).

Parish nurses have strategic roles to play in engendering hope and coping in their patients living with advanced breast cancer in a country like Nigeria, however, not much is known about that particular experience. Faith-based organizations through their parish nursing activities are well poised to provide holistic care to members of their congregation, particularly women living with advanced breast cancer. The purpose of this paper is to explore the role of the community- engaged faith researcher in enhancing hope in women living with advanced breast cancer in Nigeria. Living with an illness like advanced breast cancer requires appreciable healing resources and hope has been identified as an important concept "that nurses have the potential to facilitate or sustain in others” (Tutton, Seers, \& Langstaff, 2009, p. 120).

\section{Parish Nursing}

Parish nursing offers holistic care within the faith community. It is a specialized practice of professional nursing, addressing the spiritual, physical, and emotional health needs of clients within a faith community (King, 2011). The faith community is a natural support system that provides for all members, irrespective of their age, ethnic background, or socioeconomic level, health care services that they might not otherwise receive (Striepe, 1993). Throughout history, health and healing have been integral parts of the religious practices of faith communities. Parish nursing is rooted in the Judeo-Christian tradition (Patterson \& Slutz, 2011). In ancient times, the beliefs of Buddhism, Hinduism, Judaism, Christianity, and Islam were used to treat sick individuals (Shores, 2014). The nuns, deaconesses, and other consecrated religious women who promoted holistic health in their parishes began what is now known as faith community nursing or parish nursing (Shores, 2014). Florence Nightingale advanced social activism for health promotion and actively encouraged nurses to honour the psychological and spiritual aspects of patients while providing healthcare (Balint \& George, 2015; Pappas-Rogich \& King, 2014). In the 1960s, Reverend Granger Westberg, a Lutheran pastor affiliated with the College of Medicine, University of Illinois (Chicago, USA), was instrumental in starting holistic health clinics. These clinics were efficient and effective because the nurses understood and connected the languages of science, health, and religion (Shores, 2014).

A parish nursing specialty challenges the nursing profession to reclaim the spiritual dimension of the health care system so as to provide whole-person care. Parish nursing also challenges the faith community to restore its healing mission. This is because faith-based or parish nursing is a specialty nursing practice, which combines the concepts of professional nursing with the faith-based community to provide holistic care. The faith-based healing mission provides services by integrating faith and healing. From birth to death, in times of stress, in health and illness, and in joy and sorrow, the faith-based healthcare ministry uses presence as a powerful tool. Spiritual formation, which is an essential aspect of the ministry, is ongoing (Pappas-Rogich \& King, 2013).

The American Holistic Nurses Association (2007) described the goal of parish nursing as the treatment and healing of the whole person by recognizing the interconnectedness of body, 
mind, spirit, and the environment. Some of the strategies used for carrying out this goal are health education, health counselling, home visitation, integration of health and faith, advising referral, health advocacy, initiating support groups, and coordinating various groups within the faith community (Pappas-Rogich \& King, 2013). What distinguishes parish nursing from other nursing specialties is that parish nursing intentionally integrates body, mind, and spirit so as to create wholeness, health, and a sense of well-being even when the patient's illness is not cured (King, 2011). The focus of parish nursing is to promote health in line with the values, beliefs, and practices of the faith community; "this specialty practice holds that all persons are sacred and must be treated with respect and dignity" (Pappas-Rogich \& King, 2013, p. 228). In line with these beliefs, the parish nurse serves, advocating with compassion, mercy, presence, and justice. Parish nursing assists and supports individuals, families, and communities in becoming more active partners in the stewardship of personal and communal health. Parish nursing has been described as holistic care (King, 2011). Maitlen, Bockstahler and Belcher (2012) used a community-based participatory research method in parish nursing. Their findings indicate that the application of community-based participatory research principles helped the parish community to develop, implement, and evaluate effective community interventions within the faith based community. Following the same trend, faith-based, community-engaged researchers have a role to play in addressing the challenges of poverty and social stigma that affect the outcomes for women with advanced breast cancer in Nigeria.

\section{Breast Cancer}

Breast cancer is the most common cancer among women in developing countries and the second most common cancer globally (WHO, 2013a). It was estimated that approximately two million new breast cancer cases were diagnosed in 2012. This number accounted for $25 \%$ of all cancers (Ferlay et al., 2015; WHO, 2016). Predictions based on GLOBOCAN 2012 suggest that there will be an increase to 19.3 million new breast cancer cases per year by 2025 . More than half of all cancer incidences (56.8\%) and cancer-related deaths (64.9\%) occurred in less developed regions of the world in 2012 (WHO, 2013b). Across world regions, there is disparity and inequality in breast cancer incidence. The rate ranges from 27 per 100,000 in Middle African and Eastern Asia to 96 per 100,000 in Western Europe (Ferlay et al., 2015). However, breast cancer mortality rates in these regions are almost identical at 15 per 100,000, which clearly indicate the fact of poorer outcomes in Middle Africa and Eastern Asia (Ferlay et al., 2015). Breast cancer is the second cause of cancer-related deaths in developed countries (Ferlay et al., 2015). It is the fifth cause of cancer-related deaths globally (WHO, 2016).

Women in lower middle-income countries like Nigeria usually present with late or advanced stages of the disease (Cleary et al., 2013; Taib, Yip, \& Low, 2014). Advanced stages are described as stage 3 and stage 4 of the disease, when cancerous cells have spread to the lymph nodes and infiltrated other distant sites in the body (Willis, Lewis, $\mathrm{Ng}$, \& Wilson, 2015). Some of the factors responsible for the late stage of disease at presentation are lack of breast cancer awareness programs, lack of breast health education programs, social barriers, misconceptions, and taboos about breast cancer treatment outcomes, fear of losing an employment, inadequate 
government support, lack of adequate infrastructure and resources for routine screening, lack of standardized treatment protocols and guidelines, poor follow-up, and lack of accurate data (Tfayli, Temraz, Abou Mrad, \& Shamseddine, 2010). Other factors that may be responsible for the increase in incidence rates are the adoption of Western lifestyles that tend to encourage and promote delaying childbearing, decreasing the number of children, reducing physical exercise, and changes in dietary habits (Porter 2008). For instance, as more women enter the workforce, they tend to exert more control over their reproductive lives thereby delaying childbearing. Women also shorten the period of breastfeeding, and they give birth to a fewer number of children. With an improvement in nutrition, the age of menarche decreases while the age of menopause increases. These changes are some of the factors that are associated with the risk of developing breast cancer (Porter 2008; Yip \& Taib, 2012). Because of economic and resource constraints globally, the ability to improve early detection, diagnosis, and treatment of breast cancer is limited despite significant scientific advances (Anderson \& Jakesz, 2008). With an increase in life expectancy and reduction in mortality from infectious diseases, it is predicted that there most likely will be an increase in the incidence of breast cancer in lowmiddle-income countries (Igene, 2008; Youlden, Cramb, Yip, \& Baade, 2014).

In low middle-income countries like Nigeria, the poor prognosis of metastatic breast cancer is related to the stage of disease at presentation and the limited diagnostic and treatment capacities (Anderson et al., 2008). For metastatic breast cancer, the cure is usually not a realistic treatment outcome (Rayson et al., 2011). However, "site-specific interventions aimed at prolonging life, supportive care measures aimed at the treatment of side effects of therapy, both physical, psychological, and palliative care measures including pain management, psychosocial and spiritual issues, can enable patients to maintain a reasonable quality of life" (Cleary et al., 2013, p. 617). Because of the available treatment options, palliative care in breast cancer is usually prolonged. This implies that suffering will be prolonged for women with advanced breast cancer because of inadequate infrastructure and resources (Yip \& Taib, 2012).

Findings from studies by Jedy-Agba et al. (2012) indicated that the most common cancer in women in Nigeria from 2009-2010 was breast cancer. In Nigeria, 70-79\% of breast cancer patients still present with advanced disease (Adesunkanmi, Lawal, Adelusola, \& Durosimi, 2006; Adisa et al., 2011; Jedy-Agba et al., 2012). Advanced stages of disease can give rise to limited treatment options and poorer outcomes. Many factors are responsible for the advanced stage of disease presentation in Nigeria. Delays in the presentation may come from the patients; it may also come from the healthcare provider who may be responsible for delays in referrals and treatments (Adisa et al., 2011; Ezeome, 2010). Many factors contribute to patient-related delays in Nigeria. It can be related to some factors ranging from lack of awareness about breast cancer, misconceptions about breast cancer and its treatment outcomes, prolonged denial by patients, patient's socioeconomic problems, readily available alternative treatment options such as herbal and spiritual remedies, and other sociocultural issues (Adesunkanmi et al., 2006; Adisa et al., 2011; Ibrahim \& Oludara, 2012). Another problem preventing early presentation of women with breast cancer is the fear of mastectomy (Ajekigbe, 1991). Healthcare providerinduced delays may be a result of the lack of referral or delayed referrals, false reassurances

Engaged Scholar Journal: Community-Engaged Research, Teaching, and Learning 
by health personnel, and failure to obtain histology after biopsy (Ezeome, 2010; Ibrahim \& Oludara, 2012).

\section{Experiences of Women Living with Advanced Breast Cancer}

Diagnosis with advanced breast cancer can be a devastating experience, because it is often accompanied with experiences of severe physical, emotional, and psychological distress (McClement \& Chochinov, 2008). This is likely the case because the breast is a very significant organ in the body particularly because of its nurturing and aesthetic roles. Although hope has also been identified as helping individuals to cope during times of suffering and uncertainties such as in living with advanced breast cancer, and despite the fact that $70-79 \%$ of women in Nigeria living with breast cancer present with advanced stage of the disease, no literature was found to address the hope and coping experiences of this population. Therefore, the faithbased researcher has an essential role in exploring and understanding the hope experience of this population so as to make contributions in assisting these clients in living optimally despite their illness situation. However, there were findings from studies from some developing countries that can help the faith-based, community-engaged researcher to appreciate the experiences of women living with advanced breast cancer in Nigeria.

Findings from a qualitative study with eight Turkish women undergoing chemotherapy and radiation treatments as a result of breast cancer indicated that when women are diagnosed with advanced breast cancer, the diagnosis is usually accompanied by feelings and concerns for one's femininity, sexuality, appearance, capacity for nurturing, and motherhood, because of the crucial roles these aspects play in one's life (Cebeci, Yang1n, \& Tekeli, 2012). The diagnosis was perceived as a threat to life and family-functioning, as a result of potential family role and responsibility redistribution. The participants also indicated that breast cancer treatments caused uncomfortable side effects such as fatigue, pain, nausea and vomiting, and hormonal changes. In another study using the phenomenological approach conducted with thirteen Iranian women living with advanced breast cancer, the findings showed that the diagnosis was accompanied by fear, feelings of loss, uncertainty, a need for support, and emotional dizziness. The study also indicated that the spouse's reaction to the physical defects arising from advanced breast cancer treatments could negatively affect a woman's self-esteem and confidence (Joulaee, Joolaee, Kadivar, \& Hajibabaee, 2012). Participants in another phenomenological study of the lived experiences of the spouses of women diagnosed with advanced breast cancer conducted by Sprung, Janotha, and Steckel (2011) described various emotional reactions to the diagnosis of advanced breast cancer at different stages of the illness trajectory. Some of the emotional reactions were: feeling overwhelmed, anxious, depressed, and angry. The diagnosis was also accompanied by feelings of a threat toward one's independence and the role of the strong one in the family. The participants reported using "spirituality, optimism, humor, self-care, wanting to maintain control, and a head-on approach to coping with the situation" (Sprung, Janotha, \& Steckel, 2011, p. 622). Women living with advanced breast cancer who participated in the Banning and Tanzeem (2013) qualitative study to explore the psychological impact of the diagnosis of advanced breast cancer narrated that they experienced devastating psychological 
outcomes due to the public perception that cancer is a communicable disease. They also stated that they experienced negative responses from their families, had uncomfortable treatment side effects, and fears of uncertainties related to recurrence and death. Some described that they had problems with marriage and breastfeeding their babies.

In another qualitative study conducted with a group of women living with advanced breast cancer in Zambia, the participants stated that the experience of having to live with advanced breast cancer changed their lives (Maree \& Mulonda, 2015). According to the participants, the diagnosis of advanced breast cancer added a new role of cancer patient that made it difficult for them to fulfill their roles as mothers and wives. Mastectomy that resulted in their living with altered bodies added to their emotional distress (Maree \& Mulonda, 2015). Participants also stated that some side effects of chemotherapy such as hair loss, fatigue, nausea and vomiting, oral mucositis, and anorexia affected them psychologically. Some participants in the same study stated that they "lost the support of family, friends, and the church due to stigmatization” (Maree \& Mulonda, 2015, p. 28).

A narrative interview with the aim of exploring women's meaningful perception, semantic understanding, and their experiences of breast cancer in a religious context was carried out by Sadati et al. (2015). Eight women with advanced breast cancer who had had mastectomy were participants in the study. Findings from the study revealed two themes or trends associated with women who suffer from advanced breast cancer. The first was fatalism, while the second was hope and empowerment. Fatalism was a concept that was constructed immediately after the diagnosis of breast cancer. It pervaded the crisis time that started when a woman became aware of the problem (noticing a lump in the breast, breast pain, breast swelling, trying to understand the cause of these signs, and their implications). Fatalism was characterized by fragility, high anxiety, frustration, tiredness, and disintegration. Patients also exhibited sentiments regarding the concept of death, nature of life after death, guilt, comparing themselves with others who are healthy, helplessness, and questioning concerning the reasons why they got the illness. However, in a religious context, by using prayers, readings from the sacred scriptures, consultation with religious leaders, vows, and faith, fatalism took on a positive function of hope and empowerment (Sadati et al., 2015). This hope and empowerment were dependent on the support networks of family, community, and personal attitude towards life and death, in accordance with their beliefs. It was characterized by harmony and coherence in all dimensions of human life and meaningful perception of life and death. In this context, patients defined a new relationship with their God and their beliefs by engaging in reflexivity. This reflexivity had three components: continual relationship with God as a supreme being, with self, and with others, and it assisted with coping with the new condition. This coping strategy opened up a new glow to a future filled with hope and happiness. The results of the study also pointed to the important role that religion and its context play in the health domain (Sadati et al., 2015). Because of the significance and importance of the role of faith and the faith community in situations like this, the parish nurse is adequately and ideally positioned to study the hope experiences of women living with advanced breast cancer in Nigeria, a country where religion and parish nursing have a pivotal role in everyday life. 


\section{Hope}

Dufault and Martocchio (1985) defined hope as " a multi-dimensional dynamic life force characterized by a confident yet uncertain expectation of achieving a future good, which to the hoping person, is realistically possible and personally significant" (p. 380). Chi (2007) also defined hope as a "profound feature of human life that allows the living to keep on living and the dying to die more comfortably and with dignity" (p. 2). Folkman (2010) described hope as being a contextual and complex concept that waxes and wanes, as having a cognitive base that contains information and goals, as generating energy, as having a motivational quality, as having both negative and positive emotional tones due to the possibility that what is hoped for might not be realized, and as having basis in religion or spirituality whereby it can be seen as equivalent to faith.

Dufault and Martocchio (1985) identified two categories of hope namely generalized hope and particular hope. Generalized hope was described as a feeling of general well-being. It is faith in the future that provides protection against despair and protects an individual by casting a positive glow on life. Generalized hope is influenced by personality disposition, a developmental history that entails coming through past stressful situations quite well. A particularized hope, on the other hand, is concerned with a particular object of hope such as hope for a cure, or hope for pain relief. It helps people to put their significant life issues in order of priority. This category of hope assists in restoring meaning to life, and it also encourages commitment to something that expands beyond here and now (Martocchio, 1985). When particularized hope is threatened, a generalized hope can rescue the hopeful person. The two categories of hope share six components: affective, cognitive, behavioural, affiliative, temporal, and contextual (Dufault \& Martocchio, 1985). Folkman (2010) identified a third category of hope called "situational hope or goal-specific hope" which is obtained through "a process of revising goals by letting go of targets that are no longer tenable in identifying and obtaining meaningful and realistic goals that are adaptive for coping in the present situation" (p. 5). Such a situation can enable a person to have confidence that whatever he/she is going through presently can also be managed well (Folkman, 2010). Goal-specific hope is influenced by some factors such as: "beliefs, personality disposition, previous experience with stress, meaning of what is currently at stake, what else is going on in the person's life, interactions with significant others, and the quality of patient-caregiver communications during the period" (p. 6). Hope is affected by factors such as family, friends (social support) and religious beliefs (Denewer, Farouk, Mostafa, \& Elshamy, 2011). From the perspectives of Chinese patients living with advanced cancer, hope consists of five components: "living a normal life, social support, actively letting go of control, reconciliation between life and death, and well-being of significant others" (Mok et al., 2010, p. 3). Hope variables can be located along a continuum of hopelessness and hopefulness. Hope as defined by the participants in this study can be partly universal and it can also be partly cultural (Mok et al., 2010).

Health and hope are closely and positively linked. Hope has also been identified as an important coping strategy for enhancing the quality of life in cancer patients (Herth, 2000). Therefore, increasing hope is an important and a core value in healthcare (Nekolaichuk, Jevne, 
\& Maguire, 1999). Each person as part of being human, experiences hope. However, the nature of this experience is highly individualized. Therefore, healthcare professionals need to be able to capture the uniqueness of the experience in their clients (Nekolaichuk et al., 1999). This is important because the level of distress experienced by women living with advanced breast cancer varies from woman to woman.

Antecedents to hope identified by Alidina and Tettero (2010) are "a stressful stimulus such as loss, suffering, uncertainty, connectedness with God, positive personal attributes.... a sense of meaning and optimism" (p. 3). Miller (2007) also identified the following antecedents of hope: "a pivotal life event, stressful stimuli such as loss, major decisions, hardship, suffering, uncertainty, philosophy of life that conveys a sense of meaningfulness, sense of optimism, and personal beliefs that growth results from struggle, and connectedness with God" (p. 3). Acknowledgement of threat according to Miller (2007) is a stimulus for hope and key to suffering. Individuals usually monitor themselves and the environment for signs that reinforce hope in the process of hoping. Such signs can come from supernatural signs, physiological signs, or the behaviours of supportive others. Threats to hope identified by Miller (2007) include: "pain, uncontrolled symptoms, spiritual distress, fatigue, anxiety, social isolation, loneliness, and perceptions of hopelessness from powerful others such as the health team and the family" (p.3). All persons need hope throughout the individual's life cycle (Miller, 2007).

\section{Hope and Advanced Breast Cancer}

There is paucity of literature on the hope experiences of women living with advanced breast cancer in Nigeria. However, findings from Kashani et al. (2014) suggested that patients living with advanced breast cancer suffer from distress, stress, and anxiety during and after treatment. However, creating and promoting hope experience in the patients resulted in a reduction of distress, re-description of the future, having a meaningful life, increasing tranquility, and increasing energy levels. The findings from the study also indicated that hopeful people have more commitment towards their mental health, satisfaction with life, and higher adaptation. When confronted with adverse events, they seek several sources of support and therefore experience less mental suffering. In a qualitative research study conducted by Lee (2001) to assess the relationship between fatigue, hope, and psychological adjustment in 122 Korean women receiving chemotherapy and radiation therapy for advanced breast cancer, the findings from the study indicated that hope was a significant factor affecting adjustment in the population studied. Findings from Hasson-Ohayon, Goldzweig, Dorfman, and Uziely (2014) study of women with breast cancer and their spouses indicated that social support and hope were important contributors to the psychological well-being of the study participants. The study findings also showed that hope mediated the relationship between social support and depression. For the participants, hope was an inner resource. Higher levels of social support were associated with more hope, and this hope was associated with lower depressive symptoms. In another study conducted by Chen, Komaromy, and Valentine (2015) with older Chinese patients living with advanced cancer, hope was identified as a vital resource in helping the participants to cope with advanced cancer. The hope experiences of the participants were 
sustained through interpersonal connectedness and supportive relationships. Participants in Schapmire, Head, and Faul (2012) phenomenological exploratory study identified hope and encouragement from supportive and compassionate healthcare providers as helping them in their struggles with advanced cancer.

Participants in a qualitative study that explored the experiences of women living with advanced breast cancer have described hope as the heart of palliative care that can thrive during terminal illness even when no cure is possible (Maree \& Mulonda, 2015). Participants also narrated that they experienced various losses such as loss of femininity, physical strength, roles, and support that changed the lives they lived before becoming ill. They battled through the treatment such as chemotherapy, and they feared stigmatization, "yet receiving treatment and care brought hope" (Maree \& Mulonda, 2015, p. 29).

Hope and coping are interdependent particularly under conditions of a prolonged stressful situation such as living with advanced breast cancer (Folkman, 2010). Knowing that one has a severe disease often changes how things have been for the patient, the patient's family and friends. This is particularly the case because the world they have known has changed. The future is suddenly filled with uncertainties about what lies ahead, and how it will affect the physical, psychological, and spiritual well-being of the patient and their significant others (Folkman, 2010). When living with a stressful condition like advanced breast cancer, if the patient perceives a favourable outcome, the hope level will likely be high. However, if the patient sees that the result of his or her illness will be unfavourable, the hope level will be most likely to be low or even absent. In such situations, the patient initiates a reappraisal process of his or her personal strength, opportunities, and other benefits that can improve the perceived outcome. This process tends to give hope a stronger foothold within the individual's psychological circumstances (Folkman, 2010). Kim et al. (2011) carried out a study to evaluate the relationship between hopefulness, and immune function in a group of women living with early stages of breast cancer. 196 Korean women diagnosed with breast cancer were participants in the study. Findings showed that hopeful attitude might be associated with strong cellular immunity in the population studied. Hopefulness was strongly associated with lower level of depression and a higher quality of life. The authors concluded the study by stating that hopefulness might be related to actual better clinical outcomes of breast cancer patients through strong cellular immunity enabling resistance to the adverse effects of the illness on the body.

\section{Enhancing Hope}

Hope has been viewed not only as a coping strategy for people living with advanced cancer but also as associated with dignity in dying patients (Alidina \& Tettero, 2010). It is a precondition for health, and it alleviates suffering in different forms. It is seen as nourishment for vitality, which is the core fabric of health (Lindholm, Holmberg, \& Mäkelä, 2005). For women struggling with advanced breast cancer, the major sources of hope are family, friends, healthcare providers, fellow workers, fellow patients, and others who share the same destiny (Lindholm et al., 2005). The concept of faith was identified to be crucial to hoping in a group of terminally ill patients. 
That is faith in God, belief in the afterlife, confidence in the family and friends, as well as trust in healthcare providers. Findings from Jafari et al. (2010) with 120 cancer patients revealed a significant relationship between spiritual well-being, hope, and life satisfaction. The results of the study suggested that more emphasis should be placed on spiritual, religious, and existential variables so as to enhance the psychological adaptation of cancer patients, thereby promoting their health level and life satisfaction. Empathetic and caring relationships with patients based on trust promote hope in the terminally ill (Herth, 2004). The study by Herth (2004) also identified the uniqueness of faith for each person.

Herth (2000) identified some hope enhancing strategies that nurses can use while taking care of cancer patients. Some of those activities include: establishing a caring and supportive environment; encouraging patients to become aware of and express their fears, questions, expectations, and hopes; assisting patients to identify areas that promote hope as well as areas of threats to hope in their lives; helping patients to recognize the dialectic relationship between hope and hopelessness; assisting patients to acknowledge the interdependence of the influence of family and friends; supporting patients to identify the resources that are available in the community; encouraging activities that enable patients to reflect on the meaning and purpose of life, death, and suffering; encouraging activities that help patients to identify and appreciate their sources of strength; encouraging activities that are geared towards appreciation of the positive role of interaction with nature and positive memories; providing information that are geared towards increasing the patient's cognitive understanding of their illness, treatment options and control of symptoms; and light-heartedness. Other hope enhancing strategies identified in literature include: inviting and talking with patients about hope, telling stories about hope, listening and being willing to walk with patients through their pain and illness, maintaining a positive nurse-patient relationship, journeying with patients and building trust over time, providing honest and accurate information, controlling pain, being knowledgeable about patients cancer, answering their questions, using humour appropriately, value clarification, supporting their dignity, affirmation of their worth, and caring for the patients in a holistic way (Kylmä, Duggleby, Cooper, \& Molander, 2009; Maree \& Mulonda, 2015; McClement \& Chochinov, 2008; Turner \& Stokes, 2006). Maree and Mulonda (2015) stressed that the understanding of hope in the caregivers' lives will help them to nourish, enhance, and sustain it in others. Turner and Stokes (2006) argued that the ways in which these strategies are used depend on the context. For example, those who work in acute care settings can facilitate and enhance hope in their patients by talking with them, using therapeutic touch, giving them encouragement, offering them choices, listening to them, and maintaining a positive attitude when providing care. While nurses working in long-term settings can facilitate and enhance hope in their patients by showing the patients: love, affection, empathy, Other ways in which nurses can enhance hope in their patients sharing pleasant memories, developing relationships of trust, and making connections that happen at the heart level.

Hope-shattering activities identified by McClement and Chochinov (2008) included: inadequate pain management, heightened anxiety, depression, ineffective coping, reduced quality of life, hopelessness, and poor communication with care providers. Other hope 
hindering activities identified in literature are: abandonment, loneliness, devaluation of personhood, uncontrollable pain, discomfort, treating patient in a disrespectful way, being unconcerned about patient's situation, giving discouraging facts without offering assistance or the way out. These hope-shattering activities should be avoided (Alidina \& Tettero, 2010).

\section{Enhancing Hope in Patients Living with Advanced Breast Cancer through Parish Nursing}

What makes the holistic approach to care of parish nursing different from other nursing specialties is the key application of spiritual care. Parish nursing activities closely attend to the inseparability of the physical, emotional, and spiritual health and well-being of their clients. The clients of the parish nurse can be individuals, families or groups within the faith community (Bergquist \& King, 1994). Those who engage the services of the parish nurse do so because they seem to have seen it as an extension of the church. Because the church is vital to their lives, they naturally accepted the parish nurse and the services provided (Scott $\&$ Summer, 1993). In response to a research question on why clients choose the parish nurse for healthcare services, the participants responded that the care they received from the parish nurse was holistic that is physical, emotional, and spiritual. The respondents stressed that they appreciated the religious components to programs and healing services (King, 2011). The ways in which the parish nurse makes the faith community to become a caring community are by mobilizing and working with church committees, pastors, and parishioner volunteers to assist faith community members in need (Bergquist \& King, 1994). Major parish nursing interventions are caring, support and social support. Caring which involves making oneself available to the client is of particular importance because it is an indication that the client is valuable (Bergquist \& King, 1994).

There should be cooperation between parish nursing activities and the local hospitals so as to create a link between them. Parish nurses are expected to "assist local church pastors in their hospital visitations, work with hospital chaplains, and interact with the hospital's social services or discharge planning department" (Nelson, 2000, p. 3). This will help in ensuring a smooth transition to the home setting. After assessing their clients, parish nurses can refer the clients to a pastor of client's choice for spiritual care and interventions (Fehring \& Frenn, 1987). They can also assist the client in seeing their condition from a religious perspective. Other ways of providing care include the use of prayer, the use of touch when it is appropriate, visiting homebound clients, making home visits with pastors, and teaching and encouraging family members to care for their family members at home (Fehring \& Frenn, 1987). Prayer and presence can enhance increased feelings of peace, hope, worth, self-esteem, strength, importance, and improved view of the purpose of life in the parish nurses' clients (Scott \& Summer, 1993).

In a qualitative study by Shores (2014) involving 35 faith community members, six clergy representatives, and 11 faith community nurses to identify the spiritual nursing interventions used in the local faith community nursing program, the participants identified the following interventions: Active listening, which entails the recognition of the client's verbal and nonverbal messages; coping enhancement, which requires helping the client in handling 
perceived stressors, changes, and threats that interfere with meeting roles and demands in life; dying care, which involves sitting with a dying person and his/her family, and promoting physical and psychological peace towards the end of life; forgiveness facilitation, which implies encouraging individuals to be willing to replace feelings of anger, annoyance, bitterness, envy, hostility, and resentment towards self, another person, and even a higher power with feelings of beneficence, understanding, empathy, compassion, generosity, and humility; grief work facilitation, which consists of the resolution of a significant loss. Shores also describes the need for family members to come together during important anniversaries to have a remembrance service. Other interventions that impact spiritual care includes: "anxiety reduction strategies, calming techniques, counselling services, crisis interventions, decision-making support, and emotional support" (Shores, 2014, p. 304).

The family is a very crucial resource in handling stress and crisis, particularly during times of illness like advanced breast cancer. The parish nurse can help families cope, remain supportive, and express their fears during times of distress arising from a loved one living with advanced breast cancer. The role of parish nursing is to practice, promote, and ensure that family members understand and adopt those strategies that will ensure adaptive coping. Such strategies are the ones that relieve acute anxiety, confusion, and hopelessness; strategies that enable alternative solutions to problems; strategies that lead to a new or larger repertoire of coping behaviours; and strategies that restore hope and a sense of the future (Dufault \& Martocchio, 1985). They can be invited to share insights into how well the family has coped with the difficult situation, and how they have been using available resources to accomplish the tasks that the family was unable to perform (Martocchio, 1985).

\section{The Role of the Faith-Based, Community-Engaged Researcher}

In a country like Nigeria, where a high percentage of women present with an advanced stage of the disease, community-based research is needed to explore how these women cope with their illness experiences. Nigerians exhibit a high level of trust in their faith-based institutions. Therefore parish nursing represents a significant perspective that is valuable to many people in Nigeria. Specifically focusing on the concept of hope brings a practical and valuable psychological resource that is beneficial for individuals and families in the context of various illnesses such as advanced breast cancer (Duggleby et al., 2007; Duggleby, Williams \& Wright, 2005; Martocchio, 1985; ). However, according to Nekolaichuk et al. (1999), the nature of the hope experience is invidualized within unique contexts. This implies that women living with advanced breast cancer will experience hope in unique and diverse ways. The faith informed, community-engaged researcher, through parish nursing activities, needs to capture the uniqueness of the experience of hope particularly in women living with advanced breast cancer in a country like Nigeria. This will enable the development and testing of individualized hope-enhancing strategies that will help their clients living with advanced breast cancer cope and find meaning in their illness situation. 


\section{Conclusion}

Faith community nursing provides healthcare in a holistic manner to all clients. The clients of the parish nurse can be individuals, families, groups within the faith community, and the community as a whole. The services of the parish nurse are well accepted by members of the faith community. Diagnosis of advanced breast cancer can have both physical and emotional implications related to self-esteem, self-image, sexuality, femininity, reproductive health, and nurturing capacity. Any disease that threatens the breast will endanger a woman's sense of psychological well-being. This can be accompanied with pain, uneasiness, devastation, panic, anxiety, depression, hopelessness, fear of uncertainties, and being abandoned by loved ones.

Hope has been identified as a vital coping strategy for individuals experiencing difficult situations. It has been found to help individuals to adapt to illness, maintain a high level of wellbeing, avoid psychological hardships, and to cope with stressful, life threatening situations such as living with advanced breast cancer. Parish nurses have a strategic role to play in enhancing hope in their clients so as to help their clients to cope and find meaning in life. The provision of these activities by the parish nurse in a country like Nigeria, where healthcare infrastructure and resources are limited, will go a long way in seeing that women living with advanced breast cancer enjoy improved quality of life. Even if they have to die, the interventions of the faithbased community-engaged parish nurse will enable them to do so with dignity.

\section{About the Authors}

Sr. Agatha Ogunkorode, RN, BSCN, MN, MED, PHD (corresponding author) belongs to the religious congregation of the Sisters of St. Michael the Archangel. A female religious order of Diocesan Right with the mother house situated in the Catholic Diocese of Ekiti, in Nigeria. She has been involved in parish nursing activities in various parishes in Nigeria for about 30 years. She is currently the Sister adviser of the Catholic Nurses Guild in the Catholic Diocese of Ekiti, Nigeria. She is also a graduate student at the College of Nursing, University of Saskatchewan, Saskatoon, Canada. Email: aoo121@mail.usask.ca

Lorraine Holtslander, $\mathrm{RN}, \mathrm{PhD}, \mathrm{CHPCN}(\mathrm{c})$ is a professor and graduate chair in the College of Nursing at the University of Saskatchewan. Her clinical area is in palliative home care while the focus of her research is palliative care, grief and loss, and supporting family caregivers during bereavement. She teaches family nursing and qualitative research methods. 


\section{References}

Adesunkanmi, A. R., Lawal, O. O., Adelusola, K. A., \& Durosimi, M. A. (2006). The severity, outcome and challenges of breast cancer in Nigeria. The Breast, 15(3), 399-409.

Adisa, A. O., Arowolo, O. A., Akinkuolie, A. A., Titiloye, N. A., Alatise, O. I., Lawal, O. O., \& Adesunkanmi, A. R. K. (2011). Metastatic breast cancer in a Nigerian tertiary hospital. African Health Sciences, 11(2), 279-284.

Ajekigbe, A. T. (1991). Fear of mastectomy: The most common factor responsible for late presentation of carcinoma of the breast in Nigeria. Clinical Oncology, 3(2), 78-80.

Akin-Odanye, E. O., Asuzu, C. C., \& Popoola, O. A. (2011). Measured effect of some sociodemographic factors on depression among breast cancer patients receiving chemotherapy in Lagos State University Teaching Hospital (LASUTH). African Health Sciences, 11(3).

Alidina, K., \& Tettero, I. (2010). Exploring the therapeutic value of hope in palliative nursing. Palliative \& Supportive Care, 8(03), 353-358.

American Holistic Nurses Association (2007). Holistic nursing: Scope and standard of practice. San Francisco, USA: American Holistic Nurses Association. Retrieved from http://www.ahna. org/resources/publications/books/scopeandstandard/tabid/1938/default.aspx.

Anderson, B. O., \& Jakesz, R. (2008). Breast cancer issues in developing countries: An overview of the Breast Health Global Initiative. World Journal of Surgery, 32(12), 2578-2585.

Anderson, B. O., Yip, C. H., Smith, R. A., Shyyan, R., Sener, S. F., Eniu, A., . . Harford, J. B. (2008). Guideline implementation for breast healthcare in low-income and middle-income countries. Cancer, 113(S8), 2221-2243.

Balint, K. A., \& George, N. (2015). Faith community nursing scope of practice: Extending access to healthcare. Journal of Christian Nursing, 32(1), 34-40.

Banning, M., \& Tanzeem, T. (2013). Managing the illness experience of women with advanced breast cancer: Hopes and fears of cancer-related insecurity. European Journal of Cancer Care (English Language Edition), 22(2), 253-260.

Bergquist, S., \& King, J. (1994). Parish nursing: A conceptual framework. Journal of Holistic Nursing, 12(2), 155-170.

Cebeci, F., Yang1n, H. B., \& Tekeli, A. (2012). Life experiences of women with breast cancer in south western Turkey: A qualitative study. European Journal of Oncology Nursing, 16(4), 406-412.

Chen, H., Komaromy, C., \& Valentine, C. (2015). From hope to hope: The experience of older Chinese people with advanced cancer. Health (London), 19(2), 154-171.

Chi, G. C. (2007). The role of hope in patients with cancer. Oncology Nursing Forum, 34(2), 415-424.

Cleary, J., Ddungu, H., Distelhorst, S. R., Ripamonti, C., Rodin, G. M., Bushnaq, M. A., . . . Anderson, B. O. (2013). Supportive and palliative care for metastatic breast cancer: Resource allocations in low- and middle-income countries. A Breast Health Global Initiative 2013 consensus statement. The Breast, 22(5), 616-627.

Denewer, A., Farouk, O., Mostafa, W., \& Elshamy, K. (2011). Social support and hope among Egyptian women with breast cancer after mastectomy. Breast Cancer: Basic and Clinical Research, 5(5), 93-103.

Dufault, K., \& Martocchio, B. C. (1985). Symposium on compassionate care and the dying experience. Hope: Its spheres and dimensions. The Nursing Clinics of North America, 20(2), 379-391.

Engaged Scholar Journal: Community-Engaged Research, Teaching, and Learning 
Duggleby, W., Degner, L., Williams, A., Wright, K., Cooper, D., Popkin, D., \& Holtslander, L. (2007). Living with hope: Initial evaluation of a psychosocial hope intervention for older palliative home care patients. Journal of Pain and Symptom Management, 33, 247-257.

Ezeome, E. R. (2010). Delays in presentation and treatment of breast cancer in Enugu, Nigeria. Nigerian Journal of Clinical Practice, 13(3), 311-316.

Fehring, R. J., \& Frenn, M. (1987). Wholistic nursing care: A church and university join forces. Journal of Christian Nursing, 4(4), 25-29.

Ferlay, J., Soerjomataram, I., Dikshit, R., Eser, S., Mathers, C., Rebelo, M., . . B Bray, F. (2015). Cancer incidence and mortality worldwide: Sources, methods and major patterns in GLOBOCAN 2012. International Journal of Cancer, 136(5), E359-386.

Folkman, S. (2010). Stress, coping, and hope. Psycho-Oncology, 19(9), 901-908.

Hasson-Ohayon, I., Goldzweig, G., Dorfman, C., \& Uziely, B. (2014). Hope and social support utilisation among different age groups of women with breast cancer and their spouses. Psychology \& Health, 29(11), 1303-1319.

Herth, K. (2004). Fostering hope in the terminally ill. Nursing Standard, 19(10), 33-41.

Herth, K. (2000). Enhancing hope in people with a first recurrence of cancer. Journal of Advanced Nursing, 32(6), 1431-1441.

Holtslander, L. F., Duggleby, W., Williams, A. M., \& Wright, K. E. (2005). The experience of hope for informal caregivers of palliative patients. Journal of Palliative Care, 21(4), 285.

Ibrahim, N. A., \& Oludara, M. A. (2012). Socio-demographic factors and reasons associated with delay in breast cancer presentation: A study in Nigerian women. Breast, 21(3), 416-418.

Igene, H. (2008). Global health inequalities and breast cancer: An impending public health problem for developing countries. The Breast Journal, 14(5), 428-434.

Jafari, E., Najafi, M., Sohrabi, F., Dehshiri, G. R., Soleymani, E., \& Heshmati, R. (2010). Life satisfaction, spirituality, well-being, and hope in cancer patients. Procedia - Social and Behavioral Sciences, 5, 1362-1366.

Jedy-Agba, E., Curado, M. P., Ogunbiyi, O., Oga, E., Fabowale, T., Igbinoba, F., . . Adebamowo, C. A. (2012). Cancer incidence in Nigeria: A report from population-based cancer registries. Cancer Epidemiology, 36(5), 271-278.

Joulaee, A., Joolaee, S., Kadivar, M., \& Hajibabaee, F. (2012). Living with breast cancer: Iranian women's lived experiences. International Nursing Review, 59(3), 362-368 367

Kashani, F. L., Vaziri, S., Esmaeil Akbari, M., Zeinolabedini, N., Sanaei, H., \& Jamshidifar, Z. (2014). The effectiveness of creating hope on distress of women with breast cancer. Procedia - Social and Behavioral Sciences, 159, 201-205.

Kim, S.-W., Kim, S.-Y., Kim, J.-M., Park, M.-H., Yoon, J.-H., Shin, M.-G., Yoon, J.-S. (2011). Relationship between a hopeful attitude and cellular immunity in patients with breast cancer. General Hospital Psychiatry, 33(4), 371-376 376p.

King, M. A. (2011). Parish nursing: Holistic nursing care in faith communities. Holistic Nursing Practice, 25(6), 309-315.

Kylmä, J., Duggleby, W., Cooper, D., \& Molander, G. (2009). Hope in palliative care: An integrative review. Palliative \& Supportive Care, 7(03), 365-377.

Lee, E.-H. (2001). Fatigue and hope: Relationships to psychosocial adjustment in Korean women with breast cancer. Applied Nursing Research, 14(2), 87-93. 
Lindholm, L., Holmberg, M., \& Mäkelä, C. (2005). Hope and hopelessness -- nourishment for the patient's vitality. International Journal for Human Caring, 9(4), 33-38 36p.

Maitlen, L. A., Bocksahler, A. M., \& Belcher, A. E. (2012). Using community-based participatory research in parish nursing: A win-win situation. Journal of Christian Nursing 29(4), 222-227.

Maree, J. E., \& Mulonda, J. (2015). "My experience has been a terrible one, something I could not run away from": Zambian women's experiences of advanced breast cancer. International Journal of Africa Nursing Sciences, 3, 24-30.

Martocchio, C. B. (1985). Family coping: Helping families help themselves. Seminars in Oncology Nursing, 1(4), 292-297.

McClement, S. E., \& Chochinov, H. M. (2008). Hope in advanced cancer patients. European Journal of Cancerr, 44(8), 1169-1174.

Miller, J. F. (2007). Hope: A construct central to nursing. Nursing Forum, 42(1), 12-19.

Mok, E., Lam, W. M., Chan, L. N., Lau, K. P., Ng, J. S., \& Chan, K. S. (2010). The meaning of hope from the perspective of Chinese advanced cancer patients in Hong Kong. International Journal of Palliative Nursing, 16(6), 298-305.

Nekolaichuk, C. L., Jevne, R. F., \& Maguire, T. O. (1999). Structuring the meaning of hope in health and illness. Social Science and Medicine, 48(5), 591-605.

Nelson, B. J. (2000). Parish nursing: Holistic care for the community. The American Journal of Nursing, 100(5), 24A-24D.

Pappas-Rogich, M., \& King, M. (2013). Faith community nursing: Health and healing within a spiritual congregation. Creative Nursing, 19(4), 195-199.

Patterson, D. L., \& Slutz, M. (2011). Faith community/parish nursing. Journal of Christian Nursing, 28(1), 31-33.

Porter , P. (2008). “Westernizing” women's risks? Breast cancer in lower-income countries. New England Journal of Medicine, 358(3), 213-216.

Rayson, D., Payne, J. I., Abdolell, M., Barnes, P. J., Macintosh, R. F., Foley, T., Caines, J. (2011). Comparison of clinical-pathologic characteristics and outcomes of true interval and screendetected invasive breast cancer among participants of a Canadian breast screening program: A nested case-control study. Clinical Breast Cancer, 11(1), 27-32.

Sadati, A., Lankarani, K., Gharibi, V., Fard, M., Ebrahimzadeh, N., \& Tahmasebi, S. (2015). Religion as an empowerment context in the narrative of women with breast cancer. Journal of Religion \& Health, 54(3), 1068-1079

Schapmire, T. J., Head, B. A., \& Faul, A. C. (2012). Just give me hope: Lived experiences of Medicaid patients with advanced cancer. Journal of Social Work in End-of-Life \& Palliative Care, 8(1), 2952.

Scott, L., \& Summer, J. (1993). How do parish nurses help people?: A research perspective. Journal of Christian Nursing, 10(1), 16-19.

Shores, C. I. (2014). Spiritual interventions and the impact of a faith community nursing program. Issues in Mental Health Nursing, 35(4), 299-305.

Sprung, B. R., Janotha, B. L., \& Steckel, A. J. (2011). The lived experience of breast cancer patients and couple distress. Journal of the American Academy of Nurse Practitioners, 23(11), 619-627.

Striepe, J. (1993). Reclaiming the churche's healing role. Journal of Christian Nursing, 10(1), 4-6.

Taib, N. A., Yip, C. H., \& Low, W. Y. (2014). A grounded explanation of why women present with advanced breast cancer. World Journal of Surgery, 38(7), 1676-1684. 
Tfayli, A., Temraz, S., Abou Mrad, R., \& Shamseddine, A. (2010). Breast cancer in low- and middleincome countries: An emerging and challenging epidemic. Journal of Oncology, 2010, 490631.

Turner, D. S., \& Stokes, L. (2006). Hope promoting strategies of registered nurses. Journal of Advanced Nursing, 56(4), 363-372.

Tutton, E., Seers, K., \& Langstaff, D. (2009). An exploration of hope as a concept for nursing. Journal of Orthopaedic Nursing, 13(3), 119-127.

World Health Organization [WHO]. (2013a). GLOBOCAN, 2012. International agency for research in cancer. (IARC). Presss release \#223, December, 2013. Lyon/Geneva.

World Health Organization [WHO]. (2013b). Latest world cancer sttistics, global cancer burden rises to 14.1 million new cases in 2012: Marked increase in breast cancer must be addressed. [hppt://globocan.iarc.fr]. GLOBOCAN 2012, International Cancer Research Institute of the World Health Organization. Lyon.

World Health Organization [WHO]. (2016). GLOBOCAN 2012 (IARC). Estimated cancer incidence, mortality, and prevalence worldwide in 2012. Retrieved from http://www.globocan.iarc.fr/ pages/fact_sheets_cancer.aspx.

Willis, K., Lewis, S., Ng, F., \& Wilson, L. (2015). The experience of living with metastatic breast cancer-A review of the literature. Health Care for Women International, 36(5), 514-542.

Yip, C. H., \& Taib, N. A. (2012). Challenges in the management of breast cancer in low- and middleincome countries. Future Oncology (London, England), 8(12), 1575-1583.

Youlden, D. R., Cramb, S. M., Yip, C. H., \& Baade, P. D. (2014). Incidence and mortality of female breast cancer in the Asia-Pacific region. Cancer Biology \& Medicine, 11(2), 101-115. 